\title{
Chemical Composition and Particle Size of Grape Seed Flour and Their Effects on the Characteristics of Cookies
}

\author{
Razakou Maman ${ }^{1} \&$ Jianmei $\mathrm{Yu}^{1}$ \\ ${ }^{1}$ Department of Family and Consumer Sciences, North Carolina Agricultural and Technical State University, \\ 1601 East Market Street, Greensboro, NC, 27411, USA
}

Correspondence: Jianmei Yu, Department of Family and Consumer Sciences, North Carolina Agricultural and Technical State University, 1601 East Market Street, Greensboro, USA. E-mail: jyu @ ncat.edu

Received: May 22, 2019

Accepted: June 6, 2019 Online Published: July 2, 2019

doi:10.5539/jfr.v8n4p111

URL: https://doi.org/10.5539/jfr.v8n4p111

\begin{abstract}
This study investigated the effect of particle size and chemical composition of grape seed flour (GSF) on the physical, chemical and sensory quality of cookies. Results indicate that the chemical composition of GSF varied significantly with particle sizes and smaller particle fraction had higher ash, fat, protein and extractible polyphenol contents but lower dietary fiber. Inclusion of $2.5-10 \%$ GSF in the cookie formula enhanced darkening, increased thickness and hardness, increased polyphenol and dietary fiber contents in dose-dependent manner, but reduced diameter and consumer acceptability of cookies to various degrees. The impacts of GSF on the cookie quality and sensory properties were strongly associated with the inclusion level and particle size of GSF. Higher GSF (5\%) inclusion and smaller GSF particle size $(104 \mu \mathrm{m})$ resulted in lower consumer acceptability. To minimize the undesirable effect of GSF on cookie quality, up to $5 \%$ of GSF with average particle size $209 \mu \mathrm{m}$ is recommended.
\end{abstract}

Keywords: grape seed flour, particle size, cookies, physical properties, chemical properties, consumer acceptability

\section{Introduction}

Cookie is one of the nonperishable but unhealthy baked foods because it is high in fat and sugar but low in bioactive compounds and dietary fiber. The addition of fruit pomace to cookies, especially to those made of white flour, may significantly enrich their composition with dietary fiber and phenolic compounds and improve cookie's nutritional value (Tańska et al., 2016). Some studies have been done to improve the antioxidant activity of cookies using grape pomace (Acun \& Gul, 2014; Zhu et al., 2015; Kuchtová et al., 2016). Our previous study with bread model shows that the bread with $5 \%$ grape pomace had similar loaf volume but darker color compared to the control, but increasing grape pomace content to $10 \%$ in the bread formula resulted in reduced preference in both taste and texture of the bread (Smith \& Yu, 2015). In addition, grainy mouth feel was detected which suggests the need for further particle size reduction.

Grape seeds comprise about 5\% of the fruit weight (Choi \& Lee, 2009) and 37-44\% of the dry grape pomace (Yu, 2014). Grape seeds are rich in dietary polyphenols, particularly, catechins and B-type procyanidins or condensed tannins although the polyphenol composition varies with grape variety and grown location (Shi et al., 2003; Mandic et al., 2008). It is well known that these polyphenols contribute to the color and astringent taste of grapes and wine. The health benefits of grape seed polyphenols have been extensively studied worldwide. Muscadine grapes are native to the United States. Muscadine Carolos and Noble are two varieties widely used for wine making and they have thicker skins and fewer seeds compared to the Vitis vinifera wine grape varieties (Yu, 2014). The chemical composition other than polyphenols of Muscadine grape seeds were rarely reported. Therefore, it is important to have a complete understand of their chemical composition which is very important to the nutritional value, chemical and sensory properties of the target product.

Grinding is a traditional method for particle size reduction in food industry for better acceptance of final products. Particle size reduction also affects polyphenol extractability, digestibility and functional and physicochemical properties of polyphenol and dietary fiber rich food ingredients. The reduction in the particle size from 1127 to 550 micrometer resulted in increased hydration properties of coconut fiber (Raghavendra et al., 2006). Superfine grinding of red grape pomace improved the solubility, polyphenol extractability and antioxidant 
activity of the pomace (Zhao, et al., 2015). Similar results were found for ultrafine grinding of wheat bran (Zhu et al., 2010). However, it is unknown what effects the superfine grinding grape pomace/seeds have on food product development.

The hypothesis of this study was that chemical compositions of grape seed flour (GSF) fractions of different particle sizes were different, which had significant impact on the product quality and consumer acceptance of cookies. Therefore, the chemical composition including proximate composition, total dietary fiber and polyphenol composition of Muscadine Carolos and Muscadine Noble GSF of different particle sizes were determined and their effects on the quality of short bread cookies were evaluated in this study.

\section{Materials and Methods}

\subsection{Preparation of Grape Seed Flour}

Pomaces of Muscadine Carlos and Noble were kindly provided by a winery located in North Carolina, USA. The pomace was vacuum dried and seeds were separated manually from skins. The seeds were ground into powder which was separated into three fractions of different particle size ranges using a set of mesh sieves (fine: 80-100 mesh; medium: 60-80 mesh; coarse: 40-60 mesh). The medium and coarse fractions were ground and sieved again until their particles could not be further reduced. The particle sizes of different fractions of ground grape seeds were determined by Laser Particle Size Analyzer (Microtrac, Montgomeryville, PA, USA). The average particle sizes of three fractions were $104 \mu \mathrm{m}, 209 \mu \mathrm{m}$, and $486 \mu \mathrm{m}$, respectively. The GSF fractions of different particle sizes were stored in moisture proof plastic bags at $4^{\circ} \mathrm{C}$.

\subsection{Cookie Preparation}

The GSF fraction was mixed with other ingredients of short bread cookie to $2.5-10.0 \%$ using a kitchen aid to form cookie dough, thus percentage of other ingredients (all-purpose flour, baking soda, sugar, butter, egg) except vanilla extract were proportionally reduced. The dough was split into small pieces of equal weight which were rolled in small balls and pressed in a cookie cutter to the same height. The cookie dough was placed on a cookie sheet (24 per sheet) and baked in a preheated oven at $177^{\circ} \mathrm{C}$ for 20 minutes, then cooled to room temperature on the cooling shelf.

\subsection{Measurements of Physical Properties of Cookies}

After cooling, cookie weight, diameter, thickness, color and texture were measured. The cookie without GSF was used as control The weight of cookies was recorded using METTER TOLEDO AB 265-S balance after cookies were cooled to room temperature. The measurement was triplicated for each type of cookies. The diameter was measured using a ruler and the thickness was determined by a caliper. Four measurements were taken for each cookie.

Color was measured by CIEL color system using Konica-Minolta MC-3500d Spectrophotometer (Tokyo, Japan). The color of cookies denoted $\mathrm{L}^{*}, \mathrm{a}^{*}$, and $\mathrm{b}^{*}$ was determine, where $\mathrm{L}^{*}$ signifies the lightness from 0 (black) to 100 (white). The color channels, $a^{*}$ and $b^{*}$, represent true neutral gray values at $a^{*}=0$ and $b^{*}=0$, represents green and blue at negative $a^{*}$ and $b^{*}$ values, and red and yellow at positive $a^{*}$ and $b^{*}$ values, respectively. Measurements were made at 5 spots on the top side of each cookie. The results were expressed as the mean of 15 measurements ( 3 cookies per treatment).

The hardness of cookie was measured using a TA-XT2 Texture Analyzer (Texture Technologies Corporation, Scarsdale, NY). The program used was Bakery/Biscuit cutting- BIS2_KB.PRJ with the probe HDP/ BSK (Blade Set with Knife) to determine the maximum force needed to cut the cookie. The measurement was conducted in triplicate.

\subsection{Proximate Composition Analysis of Different Fractions of GSF and Cookies}

Moisture, ash, crude protein, crude fat, total carbohydrate and dietary fiber contents of GSF and cookie samples were determined using AOAC methods, and total carbohydrates were calculated by difference. The moistures were determined by vacuum drying method using an Isotemp Vacuum oven (Fisher Scientific, Georgia, USA). The crude fat contents were determined by modified AOAC Method 945.16 (AOAC, 2005) with petroleum ether as solvent using FOSS Soxtec TM 2050 Extractor (Hoganas, Sweden). The ash was determined using AOAC Official Method 923.03 (AOAC, 2005) with a Barnstead Thermolyne 30400 muffle furnace (Dubuque, Iowa, USA). The protein content was determined by a combustion method (AOAC, 2006) using PerkinElmer Series II CHN 2400 Analyzer (PerkinElmer, Inc., Waltham, MA USA) in which the total nitrogen content of the GP sample was determined. The nitrogen to protein conversion factors used for GSF and cookies were 5.46 and 5.7, respectively (Mariotti et al, 2008; Fujihara et al., 2008). Ash and protein were determined using defatted samples, 
then converted back to the non-defatted basis according to the fat contents of GSF and cookies. For each of GSF or cookie sample, the measurement was conducted in triplicate.

\subsection{Determination of Dietary Fiber of GSF Fractions and Cookies}

Total dietary fiber (TDF) of GSF and cookie was determined using the enzymatic-gravimetric method by AOAC method 991.42 (AOAC, 1996) with TDF assay Kit (Sigma-Aldrich, St. Louis, MO, USA), which uses heat stable $\alpha$ - amylase and amyloglucosidase to hydrolyze and remove starch, and protease to remove protein.

\subsection{Determination of Polyphenols of GSF Fractions and Cookies}

The polyphenols in GSF and ground cookies samples were extracted using 70\% ethanol. The sample size was $1.000 \mathrm{~g}$ for GSF and 3.000g for cookie. A two-step extraction process was used for both GSF and cookie samples as described previously (Smith \& Yu, 2015), and the extraction was conducted in triplicate for each sample. The total polyphenol (TP) concentration of the extract was determined by Folin-Ciocalteu method (Singleton et al., 1999) with small modification, and expressed as mg gallic acid equivalent (GAE)/g GP. The total anthocyanin (TA) was determined by AOAC method 2005.02 and calculated as cyanidin-3-glucoside equivalents for the samples (Lee, 2005). The total flavonoid (TF) was determined by the aluminum chloride $\left(\mathrm{AlCl}_{3}\right)$ colorimetric method and expressed as mg catechin/g sample (Hosu et al., 2014). The condensed tannin (CT) concentration was determined by Vanillin-HCl Assay and were expressed as mg catechin equivalent (mg CE)/g sample (Hagerman, 2002).

\subsection{Sensory Evaluation of Cookies}

A quantitative affective method was used to evaluate the liking of sensory attributes including color, aroma, texture, flavor and overall liking of cookies. The sensory evaluation of cookie was conducted the day after baking using 55 untrained panelists composed of students, staff and faculty members ages 18 to 55 . Each attribute was scored using a 9-point hedonic scale with 1 being dislike extremely, 5 being neither like nor dislike and 9 being like extremely. Samples were assigned 3-digit codes and were randomized served in the plate. Each participant received a total of 5 cookies consisting of 0\% GSF (control), 2.5\% GSF (104 $\mu \mathrm{m}$ ), 2.5\% GSF (209 $\mu \mathrm{m}), 5 \% \mathrm{GSF}(104 \mu \mathrm{m})$, and 5\% GSF $(209 \mu \mathrm{m})$. Water was provided for rinsing mouth between samples.

\subsection{Data Analysis}

Data of proximate composition, physical properties, and sensory evaluation were analyzed by ANOVA and Duncan Multiple Range Comparison tests using SAS 9.2 software (Cary, NC) to determine whether significant difference exist among samples containing different particle size/amounts of GSF at 5\% significance level. The relationship between cookie polyphenol contents and GSF inclusion level was analyzed by numerical regression method.

\section{Results}

\subsection{Proximate Compositions of GSF Fractions of Different Particle Sizes}

The proximate compositions of fractions of different particle size differ from each other (Table 1). Overall, finer GSF fractions had high fat, mineral and protein contents but lower carbohydrate and TDF contents regardless grape cultivar (Table 1). When the particle size was reduced from 486 um (coarse) to 209 um (medium), the fat content of increased from $8.7 \%$ to $15.45 \%$ for Noble seed and from $9.07 \%$ to $17.95 \%$ for Carolos seed flour, but further reduction of particle size did not change the fat content too much. The coarse fraction (486 um) showed highest carbohydrate, lowest fat, mineral and protein concentrations. Extensive reduction of particle size due to grinding liberate more reactive components due to cell breakage, which explains the increased fat and protein contents detected. Carlos GSF had higher TDF than Noble GSF at same particle size, but TDF decreased significantly for both Carlos and Noble GSF as particle size decreasing. The lowest TDF content $(32.32 \%)$ was observed in the fine fraction $(104 \mu \mathrm{m})$ of Noble GSF and the highest TDF content was in the coarse fraction (486 $\mu \mathrm{m}$ ) of Carlos GSF. It was reported that GSF contains 43\% of TDF (Aghamirzaei et al., 2015). At particle size 104 and 209 um, Carlos GSF showed higher TDF than total carbohydrate because the interaction between condensed tannin with protein and other components which could greatly reduce the digestibility of GSF (Yu et al., 2016). 
Table 1. Proximate Compositions and TDF of Grape Seed Flour Fractions of Different Particle Sizes

\begin{tabular}{llllllll}
\hline GSF Type & $\begin{array}{l}\text { Particle Size } \\
(\boldsymbol{\mu m})\end{array}$ & $\begin{array}{l}\text { Moisture } \\
(\boldsymbol{\%})\end{array}$ & $\begin{array}{l}\text { Crude Fat } \\
(\boldsymbol{\%})\end{array}$ & $\begin{array}{l}\text { Mineral } \\
(\boldsymbol{\%})\end{array}$ & $\begin{array}{l}\text { Crude Protein } \\
(\boldsymbol{\%})\end{array}$ & $\begin{array}{l}\text { Carbohydrate } \\
(\%)\end{array}$ & TDF (\%) \\
\hline Muscadine Noble & 104 & $6.33 \pm 0.40^{\mathrm{a}}$ & $16.70 \pm 0.05^{\mathrm{a}}$ & $5.74 \pm 0.03^{\mathrm{a}}$ & $14.35 \pm 0.08^{\mathrm{a}}$ & 56.88 & $32.21 \pm 1.79^{\mathrm{a}}$ \\
& 209 & $6.24 \pm 0.20^{\mathrm{a}}$ & $15.45 \pm 0.16^{\mathrm{b}}$ & $4.85 \pm 0.07^{\mathrm{b}}$ & $14.77 \pm 0.19^{\mathrm{b}}$ & 58.68 & $45.09 \pm 2.72^{\mathrm{b}}$ \\
& 486 & $6.68 \pm 0.08^{\mathrm{a}}$ & $8.70 \pm 0.06^{\mathrm{c}}$ & $2.80 \pm 0.04^{\mathrm{c}}$ & $10.53 \pm 0.19^{\mathrm{c}}$ & 71.29 & $59.26 \pm 0.28^{\mathrm{c}}$ \\
Muscadine Carlos & 104 & $5.03 \pm 0.36^{\mathrm{b}}$ & $17.59 \pm 0.56^{\mathrm{d}}$ & $6.33 \pm 0.02^{\mathrm{d}}$ & $15.74 \pm 0.18^{\mathrm{d}}$ & 55.32 & $48.17 \pm 0.43^{\mathrm{d}}$ \\
& 209 & $3.89 \pm 0.45^{\mathrm{c}}$ & $17.95 \pm 0.71^{\mathrm{d}}$ & $6.08 \pm 0.06^{\mathrm{e}}$ & $17.53 \pm 0.48^{\mathrm{e}}$ & 54.56 & $59.19 \pm 0.62^{\mathrm{e}}$ \\
& 486 & $4.56 \pm 0.21^{\mathrm{d}}$ & $9.07 \pm 0.62^{\mathrm{ce}}$ & $3.31 \pm 0.07^{\mathrm{f}}$ & $11.89 \pm 0.91^{\mathrm{f}}$ & 71.16 & $67.22 \pm 0.28^{\mathrm{f}}$ \\
\hline
\end{tabular}

In the same column, data with different superscript are significantly different at $\mathrm{P}<0.05$.

\subsection{Polyphenol Compositions of GSF Fractions of Different Particle Sizes}

Reducing particle size of GSF significantly increased extractability of total polyphenol TP (Fig.1A), total flavonoid TF (Fig.1B), total anthocyanin TA (Fig. 1C) and total condensed tannin (Fig.1D). The only exception is that the TA content in the fine fraction of Muscadine Carlos GSF was significantly lower than that in the medium and coarse fraction. The extractable TP, TF, CT were only $5 \mathrm{mg} / \mathrm{g}, 2.5-3.0 \mathrm{mg} / \mathrm{g}$ and $1.2-3 \mathrm{mg} / \mathrm{g}$ in the coarse GSF fractions, but they increased to $12-14 \mathrm{mg} / \mathrm{g}, 5-6 \mathrm{mg} / \mathrm{g}$ and $5-9 \mathrm{mg} / \mathrm{g}$ in medium fractions, and 18-20, $6-7,7-13 \mathrm{mg} / \mathrm{g}$ in the fine fractions. Our results are in good agreement with what reported by Brewer et al. (2014) who found that fine fraction of wheat bran had higher phenolic acid, flavonoid, anthocyanin, and carotenoid contents than coarse fraction. It was reported that crushing increased extractable TP and TF for Cabernet Sauvignon and Pinoir Sirah late seeds, but had little effect on anthocyanin extractability of Cabernet Sauvignon and reduced anthocyanin availability of Pinoir Sirah late seeds (Myeyer et al., 1997). Similar results were found in the studies of polyphenol extraction from tea and ginger, in which more TP and TF were extracted when particle size decreased from $1.18 \mathrm{~mm}$ to $0.71 \mathrm{~mm}$, but further reduction of particle size to $0.425 \mathrm{~mm}$ resulted in decreased TP and TA extractability from tea, but increase for ginger (Makanjuola, 2017). Combining our results and the findings of other researcher, we conclude that polyphenol compositions of GSF fractions of different particle sizes vary greatly which may affect the characteristics of food product if GSF is used as an ingredient in food product development.

\subsection{Effects of Particle Size and GSF Level on the Physical Properties of Cookies}

The physical properties including diameter, thickness, weight, hardness, and color of cookies were measured and the results were summarized in Tables 2. Compared with the control, cookie diameter decreased but thickness increased $(\mathrm{P}<0.05)$ in the presence of GSF although cookie weight only showed slight changes. Increasing GSF level from 2.5 to $5 \%$ reduced the diameter but increased the thickness of cookies, whereas, reducing particle size of GSF from $209 \mu \mathrm{m}$ to $104 \mu \mathrm{m}$ resulted in increased cookie diameter but did not change cookie thickness regardless the type of GSF. The hardness of cookies increased significantly in the presence of GSF and high GSF level resulted in harder cookies $(\mathrm{P}<0.05)$, especially Muscadine Noble GSF. The findings are different from the that of Acun \& Gül (2016) who found that addition of 5-15\% of whole grape pomace or 5-10\% of grape seed powder did not cause significant changes in cookie diameter and thickness. Our previous study and Hoye's study about the fortification of while bread using grape pomace and GSF also found that an increase in grape pomace or GSF replacement above 5\% of wheat flour caused significant decrease in loaf volume (Smith \& Yu, 2015; Hoye, 2009).

The mechanical texture of cookies was evaluated by measuring hardness and expressed as maximal force required to cut the cookie (Table 2). GSF cookies, especially those containing Noble GSF, were found to be harder than the control cookie $(\mathrm{P}<0.05)$. The increase of hardness with GSF concentration is marginally significant $(\mathrm{P} \leq 0.05)$ for Carlos seed cookies and smaller particle GSF fractions of GSF (104 um) had larger impact on the hardness of cookie in general with exception of Noble GSF at $5 \%$ inclusion level. The findings in this research are in good agreement with the findings of Samohvalova et al. (2016) who found that addition of grape seed powder strengthened wheat flour gluten in the dough and increased the hardness of butter biscuit. Similar results were also obtained in the studies of bread fortification using grape pomace and GSF (Smith \& Yu, 2015; Hoye, 2009). The hardness of cookies with GSF may also be attributed to the loss of moisture (Table 4) and the interaction between condensed tannin and protein (gluten) which result in the formation of tannin-protein complex. 
Table 2. The physical measurements of cookies (thickness, diameter, weight, and hardness) with GSF of Muscadine Noble

\begin{tabular}{lllllll}
\hline Type of GSF & GSF $(\%)$ & Particle Size $(\boldsymbol{\mu m})$ & Weight $(\mathbf{g})$ & Diameter $(\mathbf{c m})$ & Thickness $(\mathbf{c m})$ & Hardness $(\mathbf{k g})$ \\
\hline \multirow{3}{*}{ Muscadine Carlos } & 0 (Control) & & $30.95 \pm 0.11^{\mathrm{a}}$ & $7.62 \pm 0.05^{\mathrm{a}}$ & $1.66 \pm 0.06^{\mathrm{a}}$ & $6.54 \pm 1.12^{\mathrm{a}}$ \\
& 2.5 & 104 & $30.94 \pm 0.07^{\mathrm{a}}$ & $7.06 \pm 0.06^{\mathrm{b}}$ & $1.63 \pm 0.06^{\mathrm{a}}$ & $7.18 \pm 1.04^{\mathrm{ab}}$ \\
& & 209 & $31.21 \pm 0.10^{\mathrm{b}}$ & $7.03 \pm 0.06^{\mathrm{b}}$ & $1.57 \pm 0.05^{\mathrm{b}}$ & $6.71 \pm 0.78^{\mathrm{a}}$ \\
Muscadine Noble & \multirow{2}{*}{2.0} & 104 & $31.35 \pm 0.04^{\mathrm{bc}}$ & $6.77 \pm 0.12^{\mathrm{c}}$ & $1.73 \pm 0.15^{\mathrm{c}}$ & $7.77 \pm 1.30^{\mathrm{b}}$ \\
& & 209 & $31.41 \pm 0.08^{\mathrm{c}}$ & $6.87 \pm 0.10^{\mathrm{c}}$ & $1.70 \pm 0.07^{\mathrm{c}}$ & $7.25 \pm 1.14^{\mathrm{b}}$ \\
& \multirow{2}{*}{5.0} & 204 & $31.02 \pm 0.03^{\mathrm{a}}$ & $6.73 \pm 0.06^{\mathrm{d}}$ & $2.0 \pm 0.01^{\mathrm{d}}$ & $8.64 \pm 1.08^{\mathrm{c}}$ \\
& & 104 & $30.97 \pm 0.04^{\mathrm{a}}$ & $7.03 \pm 0.15^{\mathrm{b}}$ & $1.93 \pm 0.15^{\mathrm{de}}$ & $8.36 \pm 1.27^{\mathrm{c}}$ \\
& 209 & $31.37 \pm 0.01^{\mathrm{bc}}$ & $6.33 \pm 0.12^{\mathrm{e}}$ & $2.13 \pm 0.06^{\mathrm{f}}$ & $8.55 \pm 0.89^{\mathrm{c}}$ \\
\hline
\end{tabular}

In the same column, data with different superscripts are significantly different $(\mathrm{P}<0.05)$.

The color parameters (CIEL L*, $a^{*}$, and $b^{*}$ values) of top surfaces of cookies were presented in Table 3. All GSF containing cookies had smaller $\mathrm{L}^{*}$ values than the control, indicating reduced brightness. At same GSF level and particle size, cookies with Carlos GSF had higher $\mathrm{L}^{*}$ values, but lower $\mathrm{a}^{*}$ and $\mathrm{b}^{*}$ values than cookies with Noble GSF. Carlos GSF had less impact on L*, more impacts on $a^{*}$ and $b^{*}$ of cookies than Noble GSF, which might be caused by higher anthocyanin content of Noble GSF as shown in Fig.1C. At same particle size, the higher the GSF level, the smaller the $\mathrm{L}^{*}, \mathrm{a}^{*}$ and $\mathrm{b}^{*}$ values were. At same GSF concentration, smaller particle size resulted in reduced $\mathrm{L}^{*}$ but increased $\mathrm{a}^{*}$ and $\mathrm{b}^{*}$ values. Overall, the addition of GSF in the cookie formula resulted in cookie darkening and reducing particle size of GSF enhanced the darkening. This is in agreement with the findings of Hoye (2009) in a cookie study and the findings of Smith \& Yu (2015) in a bread study. Co-pigmentation of anthocyanins with other polyphenols can produce black pigments (Heras-Roger, et al., 2016). Oxidation of polyphenols during baking may also contribute to the darkening of GSF containing cookies.
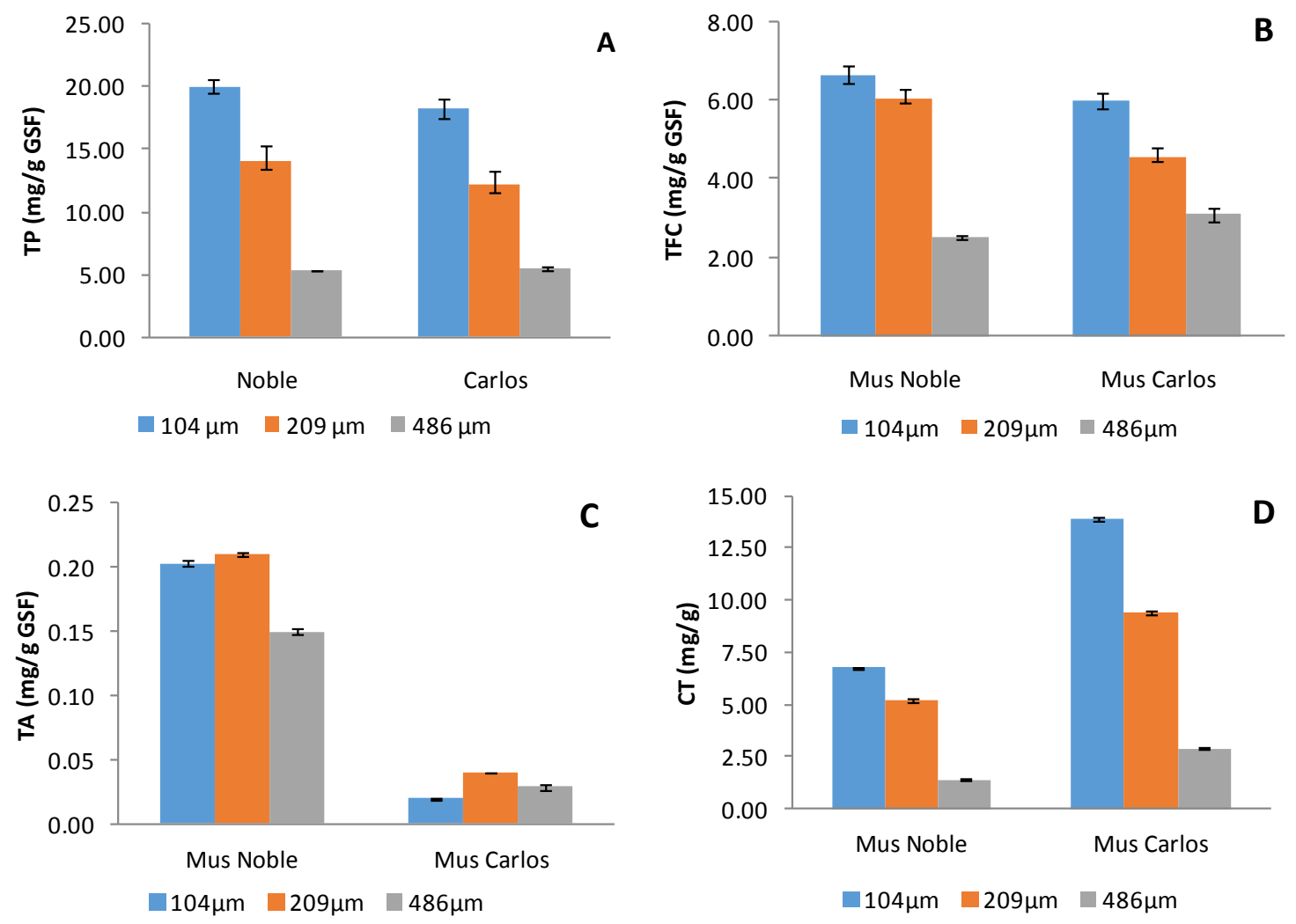

Figure 1. Effects of particle size of grape seed flour on polyphenol extractability and composition A-total polyphenol, B-Total Flavonoids, C-Total Anthocyanin, D-Condensed Tannin, Mus-Muscadine 
Table 3. Color parameters of cookies containing GSF at different concentrations and particle sizes

\begin{tabular}{|c|c|c|c|c|c|c|c|}
\hline \multirow[t]{2}{*}{ GSF Added (\%) } & \multirow[t]{2}{*}{ Particle Size $(\mu \mathrm{m})$} & \multicolumn{3}{|c|}{ Muscadine Noble } & \multicolumn{3}{|c|}{ Muscadine Carlos } \\
\hline & & $\mathbf{L}^{*}$ & a* & $\mathbf{b}^{*}$ & $\mathbf{L}^{*}$ & $\mathbf{a}^{*}$ & $\mathbf{b}^{*}$ \\
\hline $\mathbf{0}$ & Control & $54.87 \pm 0.82^{\mathrm{a}}$ & $7.92 \pm 0.11^{\mathrm{a}}$ & $16.11 \pm 0.33^{\mathrm{a}}$ & $54.87 \pm 0.82^{\mathrm{a}}$ & $7.92 \pm 0.11^{\mathrm{a}}$ & $16.11 \pm 0.33^{\mathrm{a}}$ \\
\hline \multirow[t]{2}{*}{2.5} & 104 & $41.21 \pm 0.8^{\mathrm{b}}$ & $9.0 \pm 0.33^{\mathrm{b}}$ & $20.99 \pm 0.45^{\mathrm{b}}$ & $42.17 \pm 0.43^{b}$ & $5.88 \pm 0.21^{\mathrm{b}}$ & $7.074 \pm 0.15^{\mathrm{b}}$ \\
\hline & 209 & $45.04 \pm 2.49^{\mathrm{c}}$ & $7.74 \pm 0.65^{\mathrm{a}}$ & $21.29 \pm 0.81^{\mathrm{b}}$ & $45.17 \pm 1.79^{c}$ & $6.79 \pm 0.09^{c}$ & $8.96 \pm 0.25^{\mathrm{b}}$ \\
\hline \multirow[t]{2}{*}{5.0} & 104 & $36.99 \pm 1.17^{\mathrm{d}}$ & $8.59 \pm 0.20^{\mathrm{c}}$ & $17.52 \pm 0.53^{\mathrm{c}}$ & $44.67 \pm 0.52^{\mathrm{d}}$ & $6.99 \pm 0.19^{\mathrm{c}}$ & $9.19 \pm 0.30^{\mathrm{bc}}$ \\
\hline & 209 & $46.32 \pm 0.09^{\mathrm{c}}$ & $4.57 \pm 0.15^{\mathrm{d}}$ & $7.28 \pm 0.75^{\mathrm{c}}$ & $46.58 \pm 0.43^{\mathrm{ce}}$ & $7.13 \pm 0.20^{\mathrm{d}}$ & $10.61 \pm 0.27^{\mathrm{d}}$ \\
\hline
\end{tabular}

In the same column, data with different superscripts are significantly different $(\mathrm{P}<0.05)$. ( $\mathrm{L}^{*}$ representing lightness $\left(\mathrm{L}^{*}=0\right.$ : black, $\mathrm{L}^{*}=100$ complete white); $\mathrm{a}^{*}=0$ and $\mathrm{b}^{*}=0$ representing true neutral gray values, negative $\mathrm{a}^{*}$ and $\mathrm{b}^{*}$ values representing green and blue respectively, positive $a^{*}$ and $b^{*}$ values representing red and positive yellow respectively.

\subsection{Proximate Composition of Cookies}

Table 4 shows that the inclusion of GSF significantly affected the proximate composition of cookies, but the degree of effect varied with the type, quantity and particle size of GSF. In the presence of GSF, the moisture of cookies decreased from $3.25 \%$ (control) to $0.9-1.34 \%$ depending on the quantity and particle size of GSF. Larger particle size resulted in lower water retention except cookies with 5\% Carlos GSF. The lower moisture of cookies in the presence of GSF could be caused by the high lignin content of grape seeds which has low water holding capacity (Yu, \& Ahmedna, 2013). The cookie ash contents increased with increasing GSF level and decreasing GSF particle size, which can be explained by the high ash content of GSF and the higher ash content of finer GSF fraction (Table 1). GSF inclusion slightly but significantly increased fat contents of cookie $(\mathrm{P}<0.05)$, particularly for Carlos GSF, but the effect of GSF particle size on cookie fat content was very limited. The fat content Carlos and Noble GSF fractions used for cookie making were about $18 \%$ and $16 \%$, respectively (Table 1), while the wheat flour and sugar were low- or non-fat ingredients. Therefore, partial replacement of wheat flour, sugar and butter by GSF increased fat content of cookie. Cookies containing GSF has slightly higher protein content than control cookies $(7.07 \%)$. Significantly higher protein contents were noticed at $5 \%$ and particle size $209 \mu \mathrm{m}$ of GSF. The main protein source of the original cookie recipe is wheat flour, the proportional replacement of wheat flour, sugar, and fat by GSF, which contains $10.5-17.5 \%$ of protein (Table 1), should increase the protein content of cookies. Table 4 indicates that total carbohydrate in cookies was not significantly affected by the inclusion of $2.5-5 \%$ GSF of different particle sizes.

Table 4. Proximate composition and TDF contents of cookies containing GSF of different particle sizes

\begin{tabular}{|c|c|c|c|c|c|c|c|c|}
\hline $\begin{array}{l}\text { Type of } \\
\text { GSF }\end{array}$ & $\begin{array}{l}\text { GSF } \\
(\%)\end{array}$ & $\begin{array}{l}\text { Particle } \\
\text { Size }(\mu \mathrm{m})\end{array}$ & $\begin{array}{l}\text { Moisture } \\
(\%)\end{array}$ & $\begin{array}{l}\text { Ash } \\
(\%) \\
\end{array}$ & $\begin{array}{l}\text { Crude Fat } \\
(\%)\end{array}$ & $\begin{array}{l}\text { Crude } \\
\text { Protein }(\%)\end{array}$ & $\begin{array}{l}\text { Carbohydrate } \\
(\%)\end{array}$ & TDF (\%) \\
\hline \multirow[t]{2}{*}{ Control } & 0 & & $3.25 \pm 0.09^{\mathrm{a}}$ & $0.10 \pm 0.00^{\mathrm{a}}$ & $23.07 \pm 0.20^{\mathrm{a}}$ & $7.068 \pm 0.36^{\mathrm{a}}$ & 66.56 & $2.51 \pm 0.10^{\mathrm{a}}$ \\
\hline & 2.5 & 104 & $0.99 \pm 0.15^{\mathrm{d}}$ & $0.13 \pm 0.03^{\mathrm{b}}$ & $24.21 \pm 1.20^{\mathrm{b}}$ & $7.39 \pm 0.03^{\mathrm{ab}}$ & 67.28 & $6.61 \pm 0.07^{\mathrm{b}}$ \\
\hline \multirow[t]{4}{*}{ Muscadine Carlos } & & 209 & $0.91 \pm 0.04^{\mathrm{c}}$ & $0.16 \pm 0.06^{\mathrm{bc}}$ & $24.94 \pm 0.31^{\mathrm{b}}$ & $7.52 \pm 0.06^{\mathrm{c}}$ & 66.47 & $5.77 \pm 0.23^{\mathrm{c}}$ \\
\hline & 5.0 & 104 & $1.22 \pm 0.01^{\mathrm{d}}$ & $0.23 \pm 0.04^{\mathrm{d}}$ & $24.62 \pm 2.72^{\mathrm{b}}$ & $7.68 \pm 0.09^{\mathrm{cd}}$ & 66.25 & $8.05 \pm 0.26^{\mathrm{d}}$ \\
\hline & & 209 & $1.58 \pm 0.07^{\mathrm{e}}$ & $0.20 \pm 0.06^{\mathrm{d}}$ & $25.08 \pm 0.26^{\mathrm{c}}$ & $7.87 \pm 0.00^{\mathrm{e}}$ & 65.27 & $7.39 \pm 0.22^{\mathrm{e}}$ \\
\hline & 2.5 & 104 & $1.14 \pm 0.16^{\mathrm{d}}$ & $0.27 \pm 0.01^{\mathrm{e}}$ & $23.67 \pm 0.84^{\mathrm{d}}$ & $7.20 \pm 0.09^{\mathrm{a}}$ & 67.72 & $4.57 \pm 0.07^{\mathrm{f}}$ \\
\hline \multirow[t]{3}{*}{ Muscadine Noble } & & 209 & $0.90 \pm 0.06^{\mathrm{c}}$ & $0.20 \pm 0.00^{\mathrm{d}}$ & $23.60 \pm 0.52^{\mathrm{d}}$ & $7.47 \pm 0.03^{\mathrm{b}}$ & 67.83 & $4.06 \pm 0.52^{\mathrm{g}}$ \\
\hline & 5.0 & 104 & $1.34 \pm 0.05^{\mathrm{f}}$ & $0.31 \pm 0.05^{\mathrm{f}}$ & $23.88 \pm 0.43^{\mathrm{d}}$ & $7.60 \pm 0.17^{\mathrm{c}}$ & 66.87 & $6.76 \pm 0.30^{\mathrm{b}}$ \\
\hline & & 209 & $1.08 \pm 0.05^{\mathrm{gd}}$ & $0.26 \pm 0.03^{\mathrm{e}}$ & $23.39 \pm 0.42^{\mathrm{ab}}$ & $7.62 \pm 0.13^{\mathrm{c}}$ & 67.65 & $6.89 \pm 0.34^{\mathrm{b}}$ \\
\hline
\end{tabular}

In the same column, data with different superscripts are significantly different $(\mathrm{P}<0.05)$.

\subsection{Polyphenol Contents of Cookies}

The total phenolic (TP), total flavonoid (TF) and condensed tannin (CT) in cookies were assessed, but total anthocyanin (TA) was not because TA content in GSF was too low (Fig. 1C) and anthocyanin was very unstable under alkaline condition (Oancea \& Drăghici, 2013). The TP and TF contents of cookies increased linearly with increasing GSF level and decreased with the increasing of particle sizes of GSF at each GSF particle size (Fig.2A, 2B, 2C and 2D). The CT increased with GSF inclusion level in dose-dependent manner, but not linearly (Fig. 3E, 3F). Overall, cookies with smaller GSF particles yielded higher TP, TF and CT than those with larger GSF particle size, which is correspondent to the higher TP, TF and CT contents of smaller particle fractions (Fig.1). Cookies containing Muscadine Carlos GSF showed lower TP but higher TF and CT than cookies 
containing Muscadine Noble GSF at same inclusion level and particle size. These findings suggest that GSF can be good source of flavonoid and condensed tannin of cookies, and particle size of GSF plays important role in polyphenol accessibility in food products. The smaller particle size results in better accessibility, thus better bioavailability of polyphenols. Condensed tannins are known to interact with proteins and contribute to astringent taste of cookies (Hoye, 2009; Davidov-Pardo et al., 2012). Therefore, the inclusion level and particle size of GSF need to be well controlled to ensure consumer acceptability of the product.
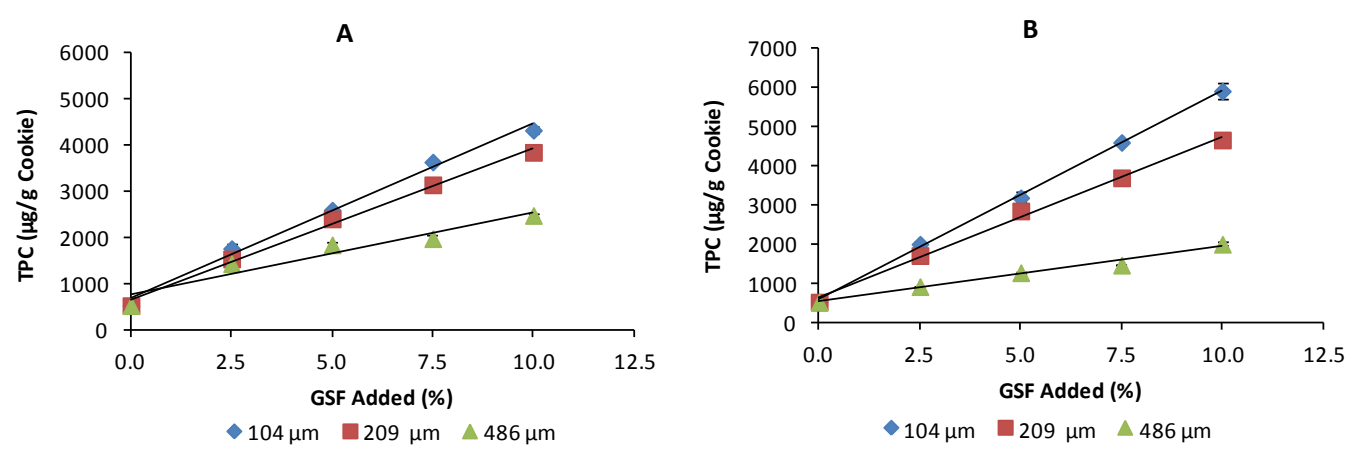

C
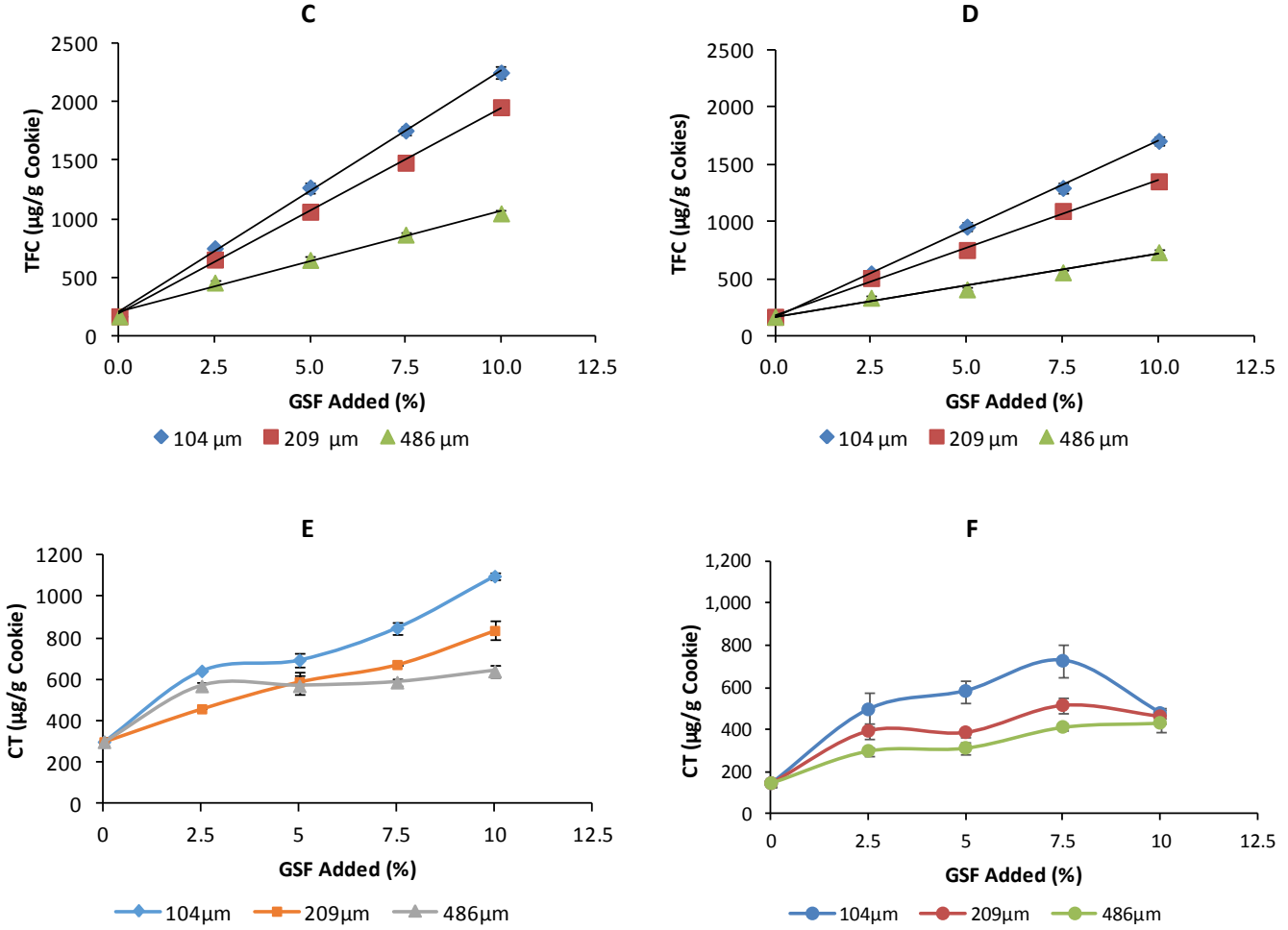

Figure 2. Effect of GSF inclusion level and GSF particle size on the total polyphenol content (TPC), total flavonoid content (TFC) and condensed tannin (CT) content of cookies

A, C, and E-cookies containing Muscadine Carlos GSF, B, D, and F-cookies containing Muscadine Noble GSF

\subsection{Total Dietary Fiber Content of Cookies}

Regression analysis of cookie TDF versus GSF level shows the TDF of cookies increased with GSF content linearly $\left(R^{2}=0.9604-0.9927\right)$ (Fig. 3). This is expected because GSF fractions contain about 32-67\% TDF (Table 1). Overall, the cookie with coarse GSF fraction showed higher TDF. At particle size 104 and 209, every 1\% addition of Noble GSF increased cookie TDF by 0.935 and $0.911 \%$, respectively; and every $1 \%$ addition of Carlos GSF increased cookie TDF 0.938 and 1.02, respectively; which were higher than the TDF of GSF. This might be attributed to the high polyphenol, particularly, condensed tannin content of GSF because polyphenols tend to interact with macronutrients to form indigestible complex and to inhibit the activity of digestive enzymes 
(Yu et al., 2016; Velickovic \& Stanic-Vucinic, 2018). Therefore, GSF can be good for TDF fortification in cookie product, but the level of inclusion must be controlled.
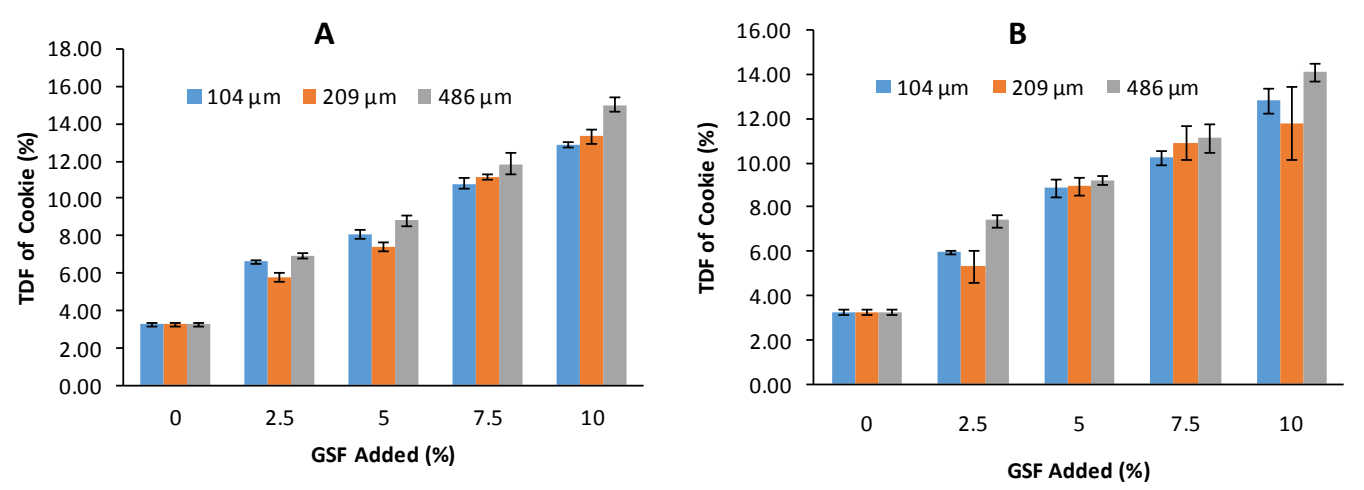

Figure 3. Effect of GSF content and particle size on the TDF of cookies

A-cookie containing Muscadine Carlos flour, B-cookies containing Muscadine Noble flour

\subsection{Consumer Acceptance of Cookies}

Cookies made with $2.5 \%$ and 5\% Muscadine Noble GSF of fine $(104 \mu \mathrm{m})$ and medium $(209 \mu \mathrm{m})$ particle sizes were evaluated by consumer test because cookies containing higher GSF levels were obviously different from control in color and flavor as tested by a focus group of 4 trained panelists. Results are summarized in Table 5 . The control cookie had the highest scores in all the sensory attributes and overall liking, followed by the cookies with $2.5 \%$ of $209 \mu \mathrm{m}$ GSF. The cookies with $5 \%$ GSF of $104 \mu \mathrm{m}$ received lowest scores. Statistically, both concentration and particle size of GSF had significant impacts on the color, taste and overall liking of cookies $(\mathrm{P}<0.05)$, but not on the aroma and texture. The particle size reduction of GSF did not obviously influence the consumer acceptance of cookies at $2.5 \%$ level, but negatively affected consumer's perception of all sensory attributes at 5\% GSF level $(\mathrm{P}<0.05)$. Overall, the level of GSF had more impact on the sensory quality and consumer acceptance of cookies than the particle size for the GSF at the concentrations and particle sizes used in this study. It was reported that the cookies containing 5\% GSF (red) was most appreciated in terms of sensorial properties and purchasing intent but the general acceptability significantly decreased as the level of GSF exceeded 10\% (Acun \& Gul, 2014). Although another study found that adding up to $15.0 \%$ (on the weight of flour) of GSF did not reduce organoleptic properties of butter biscuit comparing with reference (Samohvalova et al., 2016), it is unknown whether the GSF used in that study was from red or white grapes. Therefore, 5\% GSF might be the highest inclusion level and the fraction with average $209 \mu \mathrm{m}$ might be the best for cookie making if the GSF is from red grapes.

Table 5. Sensory Evaluation results of cookies containing Muscadine Noble GSF of different particle sizes $(\mathrm{n}=55)$

\begin{tabular}{lcccccc}
\hline Particle Size & GSF (\%) & Color & Aroma & Taste & Texture & Overall \\
\hline Control & 0.0 & $7.19 \pm 1.70^{\mathrm{a}}$ & $6.81 \pm 1.74^{\mathrm{a}}$ & $6.93 \pm 1.37^{\mathrm{a}}$ & $6.52 \pm 1.55^{\mathrm{a}}$ & $7.00 \pm 1.26^{\mathrm{a}}$ \\
$\mathbf{1 0 4} \boldsymbol{\mu m}$ & 2.5 & $6.22 \pm 1.66^{\mathrm{b}}$ & $6.67 \pm 1.77^{\mathrm{a}}$ & $6.11 \pm .49^{\mathrm{b}}$ & $6.18 \pm 1.73^{\mathrm{ab}}$ & $6.27 \pm 1.62^{\mathrm{b}}$ \\
& 5 & $5.92 \pm 1.81^{\mathrm{b}}$ & $5.92 \pm 1.53^{\mathrm{b}}$ & $5.43 \pm 1.69^{\mathrm{c}}$ & $5.92 \pm 1.81^{\mathrm{b}}$ & $5.92 \pm 1.53^{\mathrm{c}}$ \\
\multirow{2}{*}{$\mathbf{2 0 9} \boldsymbol{\mu m}$} & 2.5 & $6.36 \pm 1.89^{\mathrm{b}}$ & $6.62 \pm 1.58^{\mathrm{a}}$ & $6.44 \pm 1.69^{\mathrm{ab}}$ & $6.27 \pm 1.55^{\mathrm{ab}}$ & $6.25 \pm 1.28^{\mathrm{b}}$ \\
& 5 & $6.11 \pm 1.99^{\mathrm{b}}$ & $6.29 \pm 1.81^{\mathrm{a}^{\mathrm{b}}}$ & $5.96 \pm 1.70^{\mathrm{bc}}$ & $6.15 \pm 1.75^{\mathrm{ab}}$ & $6.22 \pm 1.56^{\mathrm{b}}$ \\
\hline
\end{tabular}

In the same column, data with different superscripts are significantly different $(\mathrm{P}<0.05)$.

\section{Conclusion}

This study indicates that the chemical composition of GSF varied significantly with particle sizes and finer fraction had higher ash, fat, protein and extractible polyphenol contents, but lower TDF content. Inclusion of GSF in the cookie formula had significant influences on cookie's physical, chemical and sensory properties. The impacts of GSF inclusion on the cookie quality and sensory properties were strongly associated with the quantity of inclusion and the particle size of GSF. Higher inclusion level (5\%) and smaller particle size $(104 \mu \mathrm{m})$ resulted 
in lower consumer acceptability. Therefore, the quantity of inclusion and particle size of GSF have to be well controlled/balanced to ensure the product quality. According to the results obtained from this study, the GSF fraction with average particle size $209 \mu \mathrm{m}$ (the fraction passes 60 mesh sieve) can be added up to 5\%. These findings provide important insights on the value added utilization of grape seed by food manufacturers or general consumers.

\section{Acknowledgement}

This study is financially sponsored by USDA-NIFA (Project \#: NC.X274-5-14-170-1), and administratively supported by Ag Research Program at North Carolina A\&T State University.

\section{Conflict of Interest}

The authors declare no conflict of interest.

\section{References}

Acun, S., \& Gül, H. (2014). Effects of grape pomace and grape seed flours on cookie quality. Quality Assurance and Safety of Crops \& Foods, 6(1), 81-88. https://doi.org/10.3920/QAS2013.0264

Aghamirzaei, M., Peighambardoust, S. H., Azadmard-Damirchi, S., \& Majzoobi, M. (2015). Effects of grape seed powder as a functional ingredient on flour physicochemical characteristics and dough rheological properties. Journal of Agricultural Science and Technology, 17, 365-373.

AOAC (1994). Association of Official Analytical Chemists, method 991.43. Total, soluble, insoluble dietary fiber in foods enzymatic-gravimetric method, MES-TRIS Buffer. AOAC International, Gaithersburg, MD.

AOAC (2005). Association of Official Analytical Chemists, method 923.03. Ash of Flour (Direct Method). In: Official Methods of Analysis, 18th ed., AOAC International Publisher, Gaithersburg.

AOAC (2005). Association of Official Analytical Chemists, method 945.16. Oil in Cereal Adjuncts. In: Official Method of Analysis, 18th ed. AOAC International, Gaithersburg, MD.

AOAC (2006). Association of Official Analytical Chemists official method 990.03. Protein (crude) in animal feed, combustion method. In: Official methods of analysis, 18th ed. AOAC International, Gaithersburg, MD.

Brewer, L. R., Kubola, J., Siriamornpun, S., Herald, T. J., \& Shi, Y. C. (2014). Wheat bran particle size influence on phytochemical extractability and antioxidant properties. Food Chemistry, 152(1), 483-90. https://doi.org/10.1016/j.foodchem.2013.11.128

Choi, Y., \& Lee, J. (2009). Antioxidant and antiproliferative properties of a tocotrienol-rich fraction from grape seeds. Food Chemistry, 114(4), 1386-1390. https://doi.org/10.1016/j.foodchem.2008.11.018

Davidov-Pardo, G., Moreno, M., Arozarena, I., Marín-Arroyo, M. R., Bleibaum, R. N., \& Bruhn, C. M. (2012). Sensory and consumer perception of the addition of grape seed extracts in cookies. Journal of Food Science, 77(12), S430-438. https://doi.org/10.1111/j.1750-3841.2012.02991.

Fujihara, S., Sasaki, H., Aoyagi, Y., \& Sugahara, T. (2008). Nitrogen-to-protein conversion factors for some cereal products in Japan. Journal of Food Science, 73(3), C204-9.

https://doi.org/10.1111/j.1750-3841.2008.00665

Hagermon, A. E. (2002). Vanillin Assay. Retrieved from https://www.users.miamioh.edu/hagermae/Vanillin\%20Assay.pdf

Heras-Roger, J., Alonso-Alonso, O., Gallo-Montesdeoca, A., Díaz-Romero, C., \& Darias-Martín, J. (2016). Influence of copigmentation and phenolic composition on wine color. Journal of Food Scicience and Technology, 53(6), 2540-2547. https://doi.org/10.1007/s13197-016-2210-3

Hosu, A., Cristea, V. M., \& Cimpoiu, C. (2014). Analysis of total phenolic, flavonoids, anthocyanins and tannins content in Romanian red wines: Prediction of antioxidant activities and classification of wines using artificial neural networks. Food Chemistry, 150(1), 113-118.

https://doi.org/10.1016/j.foodchem.2013.10.153

Hoye, C. (2009). Value-added product development utilizing Washington state grape seed flour. Retrieved from http://www.dissertations.wsu.edu/Thesis/Fall2009/c_hoye_112409.pdf

Kuchtová, V., Karovičová, J., Kohajdová, Z., Minarovičová, L., \& Kimličkov, V. (2016). Effects of white grape preparation on sensory quality of cookies. Acta Chimica Slovaca, 9(2), 84-88.

https://doi.org/10.1515/acs-2016-0014 
Lee, J. (2006). Determination of Total Monomeric Anthocyanin pigment content of fruit juices, beverages, natural colorants, and wines by the $\mathrm{pH}$ differential method: collaborative study. Journal of AOAC International, 88(5), 1269-1278.

Makanjuola, S. A. (2017). Influence of particle size and extraction solvent on antioxidant properties of extracts of tea, ginger, and tea-ginger blend. Food Science and Nutrition, 5(6), 1179-1185. https://doi.org/10.1002/fsn3.509

Mandic A. I., Đilas, S. M., Ćetković, G. S., Čanadanović-Brunet, J. M., \& Tumbas, V. T. (2008). Polyphenolic composition and antioxidant activities of grape seed extract. International Journal of Food Properties, 11(4), 713-726. https://doi.org/10.1080/10942910701584260

Mariotti, F., Tomé, D., \& Mirand, P. P. (2008). Converting nitrogen into protein--beyond 6.25 and Jones' factors. Critical Reviews in Food Science and Nutrition, 48(2), 177-84. https://doi.org/10.1080/10408390701279749

Myeyer, A. S., Yi, O. S., Pearson, D. A., Waterhouse, A. L., \& Frankel, E. N. (1997). Inhibition of human low-density lipoprotein oxidation in relation to composition of phenolic antioxidants in grapes (Viti vinifera). Journal of Agricultural and Food Chemistry, 45(5), 1638-1643. https://doi.org/10.1021/jf960721a

Oancea, S., \& Drăghici, O. (2013). pH and thermal stability of anthocyanin-based optimized extracts of Romanian red onion cultivars. Czech Journal of Food Science, 31(3), 283-291. https://doi.org/10.17221/302/2012-CJFS

Raghavendra, S. N., Swamy, S. R., Rastogi, N. K., Raghavarao, K. S. M. S., Kumar, S., \& Tharanathan, R. N. (2006). Grinding characteristics and hydration properties of coconut residue: A source of dietary fiber. Journal of Food Engineering, 72(3), 281-286. https://doi.org/10.1016/j.jfoodeng.2004.12.008

Samohvalova, O., Grevtseva, N., Brykova, T., \& Grigorenko, A. (2016). The effect of grape seed powder on the quality of butter biscuits. Eastern-European Journal of Enterprise Technologies, 61-66. https://doi.org/10.15587/1729-4061.2016.69838

Shi, J., Yu, J., Pohorly, J. E., \& Kakuda, Y. (2003). Polyphenolics in grape seeds - biochemistry and functionality. Journal of Medicinal Food, 6(4), 291-299. https://doi.org/10.1089/109662003772519831

Singleton, V. L., Orthofer, R., \& Lamuela-Raventós, R. M. (1999). Analysis of total phenols and other oxidation substrates and antioxidants by means of Folin-Ciocalteu re-agent. Methods in Enzymology, 299, 152-178. https://doi.org/10.1016/S0076-6879(99)99017-1

Smith, I. N., \& Yu, J. (2015). Nutritional and sensory quality of bread containing different quantities of grape pomace from different grape cultivars. EC Nutrition, 2(1), 291-301.

Tańska, M., Roszkowska, B., Czaplicki, S., Borowska, E. J., Bojarska, J., \& Dąbrowska, A. (2016). Effect of fruit pomace addition on shortbread cookies to improve their physical and nutritional values. Plant Foods Human Nutrition, 7l(3), 307-313. https://doi.org/10.1007/s11130-016-0561-6

Velickovic, T. D. C., \& Stanic-Vucinic, D. J. (2018). The role of dietary phenolic compounds in protein digestion and processing technologies to improve their antinutritive properties. Comprehensive Reviews in Food Science and Food Safety, 17(1), 82-103. https://doi.org/10.1111/1541-4337.12320

Yu, J., \& Ahmedna, M, (2013). Functional components of grape pomace: their composition, biological properties and potential applications. International Journal of Food Science \& Technology, 48(2), 221-237. https://doi.org/10.1111/j.1365-2621.2012.03197.x

Yu, J. (2014). Thermal stability of major classes of polyphenols in skins, seeds and stems of grape pomace. In: Jose de Sousa Camara (Eds.), Grapes: Production, Phenolic Composition and Potential Biomedical Effects (pp. 273-285). Nova Science Publishers Inc. Hauppauge, NY.

Yu, J., Mi, Y., \& Ji, S. (2016). In vitro evaluation of grape seed polyphenol extract on the digestibility of macronutrient. Journal of Health Science, 4, 167-176. https://doi.org/10.17265/2328-7136/2016.04.001

Zhao, X., Zhu, H., Zhang, G., \& Tang, W. (2015). Effects of superfine grinding on the physicochemical properties and antioxidant activity of red grape powders. Powder Technology, 286, 838-844. https://doi.org/10.1016/j.powtec.2015.09.025

Zhu, K., Huang, S., Peng, W., Qian, H., \& Zhou, H. (2010). Effect of ultrafine grinding on hydration and antioxidant properties of wheat bran dietary fiber. Food Research International, 43(4), 943-948. https://doi.org/10.1016/j.foodres.2010.01.005 
Zhu, F., Du, B., Zheng, L., \& Li, J. (2015). Advance on the bioactivity and potential applications of dietary fiber from grape pomace. Food Chemistry, 186(1), 207-212. https://doi.org/10.1016/j.foodchem.2014.07.057

\section{Copyrights}

Copyright for this article is retained by the author(s), with first publication rights granted to the journal.

This is an open-access article distributed under the terms and conditions of the Creative Commons Attribution license (http://creativecommons.org/licenses/by/4.0/). 